\title{
Knowledge, attitude and practice of health care workers on measuring adult vitamin D level, diagnosis of deficiency, and management of consequent health conditions in three ecologies of Ethiopia: a cross-sectional study
}

Wubegzier Mekonnen ${ }^{1 *}\left(\mathbb{D}\right.$, Yeweyenhareg Feleke², Yakob Desalegn ${ }^{1}$, Getahun Tarekegne $^{2}$, Biruk Lambisso $^{2}$, Jemal Haidar ${ }^{1}$ and Tewabech Zewede ${ }^{3}$

\begin{abstract}
Background: Vitamin D is essential for health and its shortage exacerbates overall mortality. Health care workers ( $\mathrm{HCWs}$ ) need to educate on its uses and sources although studies indicate their low level of practice. The main aim of this study is therefore to assess the knowledge, attitude and practice of measuring adult vitamin D status, diagnosis of deficiency and managing health consequences among HCWs in Ethiopia.

Methods: This study was conducted in three ecologies covering lowland, midland and highland districts. A total of 405 health care workers with different levels were interviewed. Tablets were used for data collection to archiving in a cloud server. Data were exported to Stata version 14 software for cleaning and analysis. Rates were computed and the Chi-square test was used to compare differences between the two groups. Binary logistic regression was used to measure the strength, direction and significance of the association between different covariates and the practice of HCWs.
\end{abstract}

Result: The level of knowledge, positive attitude and good practice in measuring adult vitamin D status, diagnosis of deficiency and managing health consequences among HCWs was 210 (51.8\%), 261(63.5\%) and 195(47.4\%) respectively. The odds of good practice in the provision of adult vitamin D service were AOR $=6.87: 95 \% \mathrm{Cl}(3.57$, 13.21) and $\mathrm{AOR}=2.20: 95 \% \mathrm{Cl}(1.23,3.92)$ times higher among HCWs in Addis Ababa and highlands compared with those working in lowlands. Good practice among clinicians was $A O R=4.26: 95 \% \mathrm{Cl}(1.48,12.25)$ times higher compared with those working in leadership positions. The likelihood was $A O R=1.96: 95 \% \mathrm{Cl}(1.19,3.23)$ times higher among those with good knowledge compared with those with poor knowledge. Besides, good practice in (Continued on next page)

\footnotetext{
* Correspondence: wubegzierm@gmail.com

'School of Public Health, College of Health Sciences, Addis Ababa University, Addis Ababa, Ethiopia

Full list of author information is available at the end of the article
}

(c) The Author(s). 2020 Open Access This article is licensed under a Creative Commons Attribution 4.0 International License, which permits use, sharing, adaptation, distribution and reproduction in any medium or format, as long as you give appropriate credit to the original author(s) and the source, provide a link to the Creative Commons licence, and indicate if changes were made. The images or other third party material in this article are included in the article's Creative Commons licence, unless indicated otherwise in a credit line to the material. If material is not included in the article's Creative Commons licence and your intended use is not permitted by statutory regulation or exceeds the permitted use, you will need to obtain permission directly from the copyright holder. To view a copy of this licence, visit http://creativecommons.org/licenses/by/4.0/. The Creative Commons Public Domain Dedication waiver (http://creativecommons.org/publicdomain/zero/1.0/) applies to the data made available in this article, unless otherwise stated in a credit line to the data. 


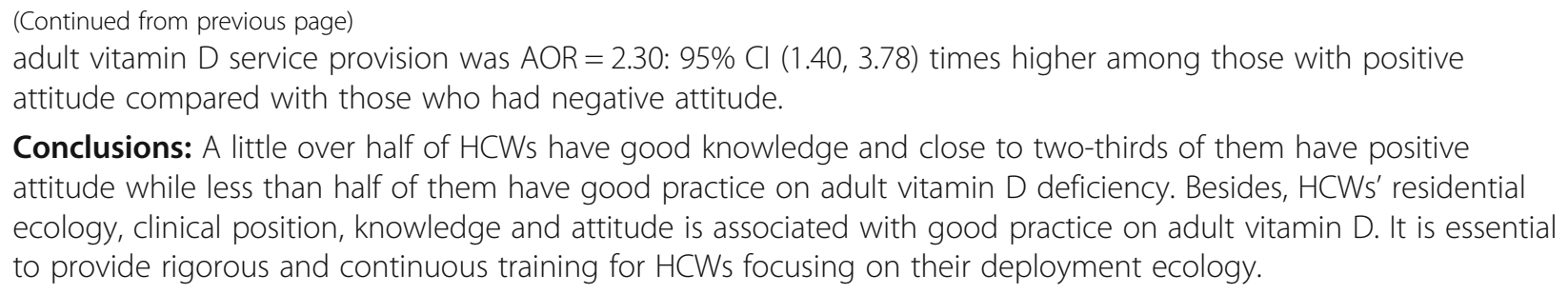

Conclusions: A little over half of HCWs have good knowledge and close to two-thirds of them have positive attitude while less than half of them have good practice on adult vitamin D deficiency. Besides, HCWs' residential ecology, clinical position, knowledge and attitude is associated with good practice on adult vitamin D. It is essential to provide rigorous and continuous training for HCWs focusing on their deployment ecology.

Keywords: Adult vitamin D deficiency, Ecology, Ethiopia

\section{Background}

Several studies showed that vitamin D is essential for bone health, extraskeletal tissues, cancer prevention, boosting immune function, infection control, and regulating cell growth, blood pressure, and cardiovascular diseases and its insufficiency has been strongly associated with increased overall mortality [1-3].

Although skin synthesis through direct exposure to ultraviolet B radiation (Direct UVB) is the vital source of vitamin $\mathrm{D}$, it may not sometimes guarantee sufficiency even among residents living in the equator as evidenced from some studies [4-7]. Therefore, there is need for having food items such as fatty fish and fish liver oil that are among the few natural food sources recommended for vitamin D.

The prevalence of adult vitamin D deficiency is increasing even in recent years $[6,7]$. The health consequences of a deficiency in vitamin $\mathrm{D}$ among adults have also been witnessed in several studies $[5,8,9]$. Health care workers (HCWs) should therefore consistently educate their communities on the uses of vitamin D, its sources, and possible health consequences. However, even recent studies done outside of Ethiopia indicated that the level of knowledge on adult vitamin D deficiency among health care workers has not been as high as expected [10-12].

On one hand, Ethiopia embarked an expansion of health care workers' training in recent decades to improve its health care delivery system although some of the training programs used expedited and abridged approaches which might compromise the professional competency of health workers [13]. On the other hand, previous studies have also showed that health care workers expressed greater concern about skin cancer which could be caused by excessive exposure to ultraviolet rays than vitamin D deficiency. A study in Australia revealed that there was some confusion in general practice regarding vitamin $\mathrm{D}$, sun exposure, sun protection and skin cancer risk. Some of the pieces of advice that general practitioners are offering may needlessly increase their patients' risk for vitamin D insufficiency or skin cancer [14-17]. Another study done in New Zealand among general practitioners indicated that concern about the potentially negative impact of skin cancer prevention on vitamin $\mathrm{D}$ status may undermine appropriate sun-protective recommendations. Other educational materials also impart knowledge on vitamin $\mathrm{D}$ and improve perception about it indicating that significantly less summer sun exposure was required for those with high sun sensitivity to achieve adequate vitamin $\mathrm{D}$, suggesting a potential positive impact of such resources. Accordingly, health education could be targeted towards such health care workers who are less likely to promote existing recommendations $[18,19]$.

Additional surveys conducted in sub-Saharan Africa and other parts of the world revealed that the level of knowledge, attitude, and practice on adult vitamin D deficiency among health care workers is not as high as expected [20, 21]. However, there is limited information with regards to this issue and no study is conducted which document the factors associated with the practice of vitamin D level measurement, diagnosis of deficiency, and the associated health consequences in the African context which warrants the conduct of such a study in one of the most populous countries with different agroecological zones.

It is therefore imperative to explore the competencies of these health care workers in giving health-related service to such specific and very important nutrients as vitamin $\mathrm{D}$. The main aim of this study is, therefore, to measure the level of knowledge, attitude, and practice on the calibration of vitamin D status, diagnosis of deficiency and management and treatment of its health consequences among health care workers deployed in three different ecologies of Ethiopia.

\section{Methods}

Ethiopia is a country with a population of over 105 million persons that has different agro-ecologies including highland, midland, and lowland areas [22]. The practice of sun exposure is strongly associated with the dressing style of people that in turn is related to the religion they confess, culture and economic activities of the society (for instance if they are engaged in outdoor activities or stay indoor most of their time). Dressing invariably differs by residence type (whether people live in 
rural or urban areas; and they reside in highland, midland, or lowland areas).

A facility-based cross-sectional design was conducted in lowland, midland, and highland areas that were purposefully selected. Addis Ababa was considered as one of the study areas for this study as it reveals the urban life style and represents the midland ecology in the Ethiopian context. Menze-Gera district represents the high land area and Qewot is a rural lowland district chosen for this study all of which are located in North Shoa zone of Amhara region.

This study enrolled health care workers deployed in the three ecologies and included health extension workers (primary health workers whose main task is disease prevention and promotion with limited curative care services), nurses, health officers, general practitioners and physicians with specialization. The sample size of 424 was calculated using a formula to calculate a single population proportion with the assumption of $50 \%$ prevalence, $95 \%$ confidence level, 5\% margin of error and $10 \%$ non-response rate.

The sample size was equally allocated to the three study ecologies. Ten health posts were randomly selected from each study ecology and interviewed all the available health extension workers who were altogether 20 in total. All public hospitals in selected rural lowland and highland study districts were also considered. The number of study participants from each professional group in health centers and hospitals was allocated using sampling proportionate to size technique.

In the case of Addis Ababa, a central referral hospital and another regional hospital was randomly selected and the remaining size of 122 study participants after the selection of 20 health extension workers was proportionally allocated to size of health care providers in these hospitals. In each selected hospital in Addis Ababa, the size was proportionally allocated by type of profession to recruit study participants from each health professional group.

Data collection questionnaire was developed after reviewing pertinent researches done on the research issue (attached as supplementary material). The questionnaire has five sections including, identification particulars of health care providers ( $\mathrm{HCPs})$, the sociodemographic characteristics of study HCPs, knowledge, attitude, and practice of them in measuring vitamin $\mathrm{D}$ status, diagnosis of deficiency and management and treatment of its conditions. The tool was pilot tested in a similar context where the actual study was not conducted. A total of six graduate students in public health nutrition with a research experience were recruited as data collectors and three MPH graduates were their supervisors. A 3 days training was provided for the field staffs which was followed by intensive supervision during data collection. An Open Data Kit (ODK) template was used for data collection which allows offline data collection. Data were submitted to the cloud server whenever there is access to the internet. Data were exported to Stata version 14 software for cleaning and analysis.

\section{Data analysis}

The study population was described using sociodemographic characteristics. Besides, composite indicators were calculated to measure the level of knowledge, attitude, and practice. The different dimensions of knowledge, attitude, and practice were described using tables and figures. In addition to this, the association of various attributes of health care workers with their practice in measuring vitamin $\mathrm{D}$ status, diagnosis of deficiency, and management and treatment of health consequences was assessed using the Chi-square test. Besides, odds ratio along with the $95 \%$ confidence interval in binary logistic regression was used to measure the strength, direction, and significance of association between socio-demographic characteristics and the practice of health care workers.

\section{Results}

From a total of 424 recruits, 405 participated in this study resulting in a $95.5 \%$ response rate. The general characteristics of the study participants are presented in Table 1. A nearly equal proportion of study participants were recruited from the three ecologies. A little over half $228(56.3 \%)$ of the health workers were females while the overwhelming majority $375(92.3 \%)$ were involved in clinical practice. Nurses constituted 152 (37.5\%) while health extension workers were $97(24.0 \%)$ and physicians $85(21.0 \%)$.

A little less than half 186 (45.3\%) of participants worked for less than 5 years in their professional career. More than nine in ten of the participated health care workers 367 (90.6\%) indicated that they have a preservice training on vitamin D although only $7(1.7 \%)$ of them reported an in-service training on vitamin $\mathrm{D}$ level measurement, diagnosis of deficiency, and management and treatment of its health consequences.

As shown in Fig. 1, the main focus areas related to vitamin $\mathrm{D}$ during the pre-service training were diagnosis of deficiency for $59.1 \%$ of providers, treatment of deficiency-related health conditions according to 55.3\% of health care workers, food fortification on vitamin D for $48.5 \%$ respondents and food supplementation according to $51.8 \%$ of providers.

\section{Knowledge of health care professional on adult vitamin D deficiency}

As shown in Table 2, nearly a quarter of health care providers $95(23.5 \%)$ believe that dietary sources are 
Table 1 Characteristics of health care providers involved in the knowledge, attitude, and practice study on adult vitamin D deficiency in three ecologic zones of Ethiopia, July 2019

\begin{tabular}{|c|c|c|c|}
\hline Variable & Response categories & Frequency & Percent \\
\hline \multirow[t]{3}{*}{ Study area: } & Addis Ababa & 140 & 34.6 \\
\hline & Highland & 135 & 33.3 \\
\hline & Lowland & 130 & 32.1 \\
\hline \multirow[t]{4}{*}{ Age group: } & $19-25$ & 71 & 17.3 \\
\hline & $25-29$ & 192 & 46.7 \\
\hline & $30-39$ & 112 & 27.3 \\
\hline & 40 and over & 36 & 8.8 \\
\hline \multirow[t]{2}{*}{ Sex of the respondent: } & Male & 177 & 43.7 \\
\hline & Female & 228 & 56.3 \\
\hline \multirow[t]{2}{*}{ Role in the facility: } & Leader/Program officer & 30 & 7.4 \\
\hline & Clinician & 375 & 92.3 \\
\hline \multirow[t]{4}{*}{ Profession: } & Physician & 85 & 21.0 \\
\hline & Nurse & 152 & 37.5 \\
\hline & Health officer & 71 & 17.5 \\
\hline & Health Extension Worker & 97 & 24.0 \\
\hline \multirow[t]{4}{*}{ Service years: } & Less than 5 & 186 & 45.3 \\
\hline & $5-9$ & 134 & 32.6 \\
\hline & $10-14$ & 56 & 13.6 \\
\hline & 15 plus years & 35 & 8.5 \\
\hline \multirow[t]{2}{*}{ Special focus on Vit D in your college training? } & Yes & 367 & 90.6 \\
\hline & No & 38 & 9.4 \\
\hline \multirow[t]{2}{*}{ In-service training on Vitamin D after graduation: } & Yes & 7 & 1.7 \\
\hline & No & 398 & 98.3 \\
\hline
\end{tabular}

\section{Yes No}

84.5
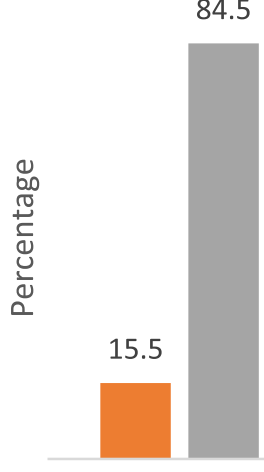

59.1

55.3
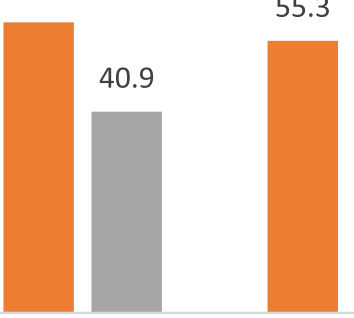

44.7

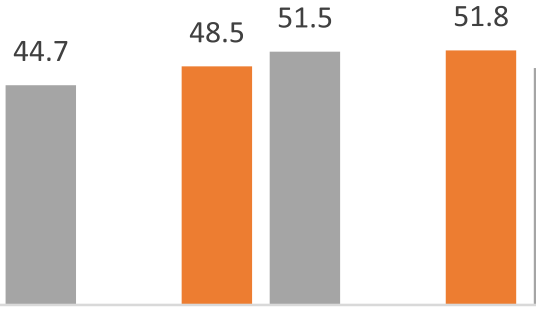

51.5

51.8

48.2

48

52
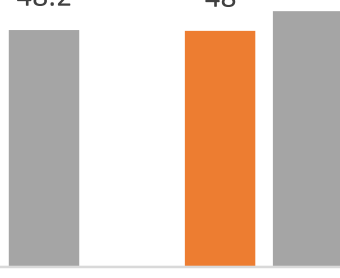

Measuring Vit D

Diagnosis of Vit D Treatment of Vit D Food fortification on

Food

Other level

Vit D supplementation

Training focus area

Fig. 1 University/College training focus areas on vitamin D deficiency for health care providers, July 2019 
Table 2 Knowledge of health care providers on adult vitamin D level measurement, diagnosis of deficiency and its management and treatment in three ecologic zones of Ethiopia, July 2019

\begin{tabular}{|c|c|c|c|}
\hline Variables & $\begin{array}{l}\text { Response } \\
\text { categories }\end{array}$ & Frequency & Percentage \\
\hline \multirow[t]{2}{*}{ Dietary sources are sufficient to maintain Vit D levels: } & Yes & 95 & 23.5 \\
\hline & No & 310 & 76.5 \\
\hline \multirow[t]{3}{*}{ Best time of day to get vitamin D from the sun: } & Morning & 391 & 96.54 \\
\hline & Mid-day & 11 & 2.7 \\
\hline & Afternoon & 3 & 0.74 \\
\hline \multirow[t]{3}{*}{ Optimal duration of sun exposure/day to get Vit D: } & $<30$ & 112 & 27.7 \\
\hline & 30 & 207 & 51.1 \\
\hline & $>30$ & 86 & 21.2 \\
\hline \multirow[t]{4}{*}{ Age groups at more risk of vitamin D deficiency: } & $\mathrm{U} 5 \mathrm{C}$ & 365 & 90.1 \\
\hline & Teenagers & 6 & 1.5 \\
\hline & Adults & 6 & 1.5 \\
\hline & Elderly People & 28 & 6.9 \\
\hline \multirow[t]{3}{*}{ Personal assertion on competency of measuring Vit D level: } & Poor & 287 & 70.9 \\
\hline & Fair & 108 & 26.6 \\
\hline & Good & 10 & 2.5 \\
\hline \multirow[t]{3}{*}{ Personal assertion on competency of Vit D deficiency diagnosis: } & Poor & 173 & 42.7 \\
\hline & Fair & 194 & 47.9 \\
\hline & Good & 38 & 9.4 \\
\hline \multirow[t]{3}{*}{ Personal assertion on Vit D management and treatment: } & Poor & 193 & 47.7 \\
\hline & Fair & 173 & 42.7 \\
\hline & Good & 39 & 9.6 \\
\hline \multirow{3}{*}{$\begin{array}{l}\text { Personal assertion on measuring Vit } \mathrm{D} \text { level, vit } \mathrm{D} \text { deficiency diagnosis and management and } \\
\text { treatment: }\end{array}$} & Poor & 195 & 48.2 \\
\hline & Fair & 185 & 45.7 \\
\hline & Good & 25 & 6.2 \\
\hline \multirow[t]{2}{*}{ Knowledge Score: } & Poor & 195 & 48.2 \\
\hline & Good & 210 & 51.8 \\
\hline
\end{tabular}

sufficient to maintain vitamin D levels and only 11 (2.7\%) think that mid-day is the best time to get vitamin D from sun exposure. However, a little more than half $207(51.1 \%)$ of the respondents revealed that $30 \mathrm{~min}$ is the optimal duration of sun exposure per day to get vitamin D. The proportion of health care workers who mentioned teenagers, adults and elderly people are risky population groups for vitamin D deficiency was 6 (1.5\%), $6(1.5 \%)$ and 28(6.9\%), respectively. Regarding the experience of HCWs on measuring vitamin D level, identifying deficiency and management and treatment of ill health consequences only $10(2.5 \%), 38(9.4 \%), 39(9.6 \%)$ and $25(6.2 \%)$ of the health care workers felt that their competency in measuring level, diagnosing deficiency, management, and treatment of ill health consequences and all of those skills mentioned above respectively was good. Overall, only $210(51.1 \%)$ of the study health care workers had a good knowledge score in this study.
Figure 2 showed inadequate sunlight exposure, the inadequacy of nutritional intake on food items rich in vitamin D, illnesses limiting vitamin D absorption, conditions impairing vitamin D conversion and impaired bone mineralization was reported as a cause of vitamin $\mathrm{D}$ deficiency by $90.1,93.8,58.8,36.5$ and $41.2 \%$ of the health workers included in this particular study.

On the other hand, Fig. 3 revealed that promotion of healthy bone growth, prevention of rickets, osteoporosis, and absorption of dietary calcium and phosphorous were reported as the uses of vitamin D by 97.8, 93.6, 88.9, 63.2 and $54.1 \%$ of health care workers participated in this study respectively.

The proportion of HCWs who described ill-health consequences of vitamin D such as osteoporosis, osteomalacia, hypocalcemia, hypophosphatemia and chronic illnesses was 95.6, 65.3, 64.7, 56.1, and 54.8\%, respectively (Fig. 4). 


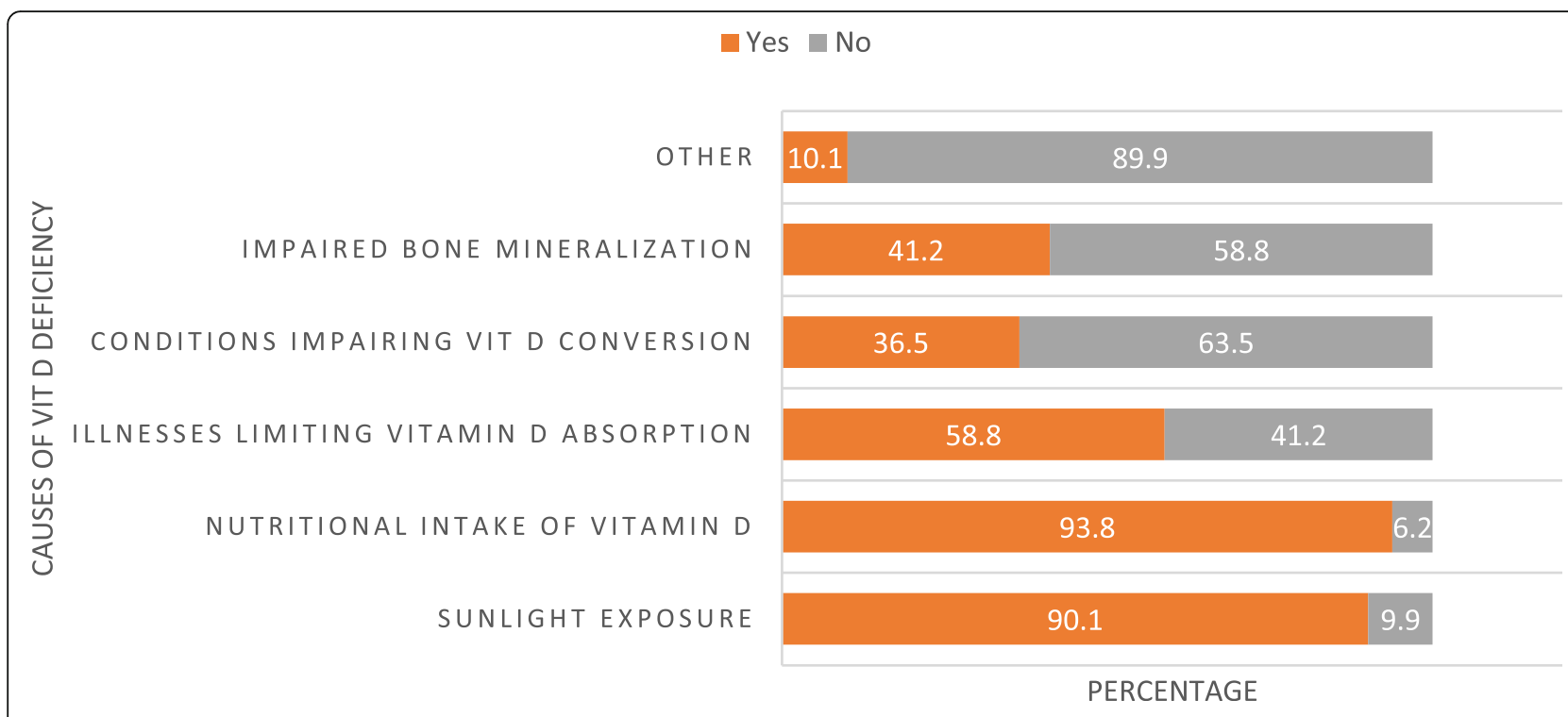

Fig. 2 Causes of adult vitamin D deficiency as reported by health care providers in three ecologic zones of Ethiopia, July 2019

When health care workers were asked about factors affecting the synthesis of vitamin D from sunlight exposure, they indicated time of day (83.2\%), clothing styles $(80.0 \%)$, season $(75.6 \%)$, sunscreen use (69.4\%), illnesses $(64.9 \%)$ and pollution $(61.2 \%)$ as main ones influencing syntheses (Fig. 5).

According to health workers, people who spent most of their time indoor (96.5\%), cover their skin when going out $(82.0 \%)$, old age persons $(78.3 \%)$ and white skin people $(29.4 \%)$ were the main population groups at more risk of vitamin D deficiency (Fig. 6).

\section{The attitude of health care workers on adult vitamin D deficiency}

Table 3 shows that $174(43.0 \%)$ of HCWs thought vitamin $D$ deficiency is a public health problem and $183(45.2 \%)$ recommended universal screening to identify deficiency. However, only $16(4.0 \%)$ believe that there is an adequate laboratory investigation to diagnose vitamin $\mathrm{D}$ deficiency in the study area. Besides, only $45(11.1 \%)$ of study participants mentioned that vitamin D supplementation is adequate in Ethiopia. Moreover, a few $66(16.3 \%)$ thought that they are adequately aware of the

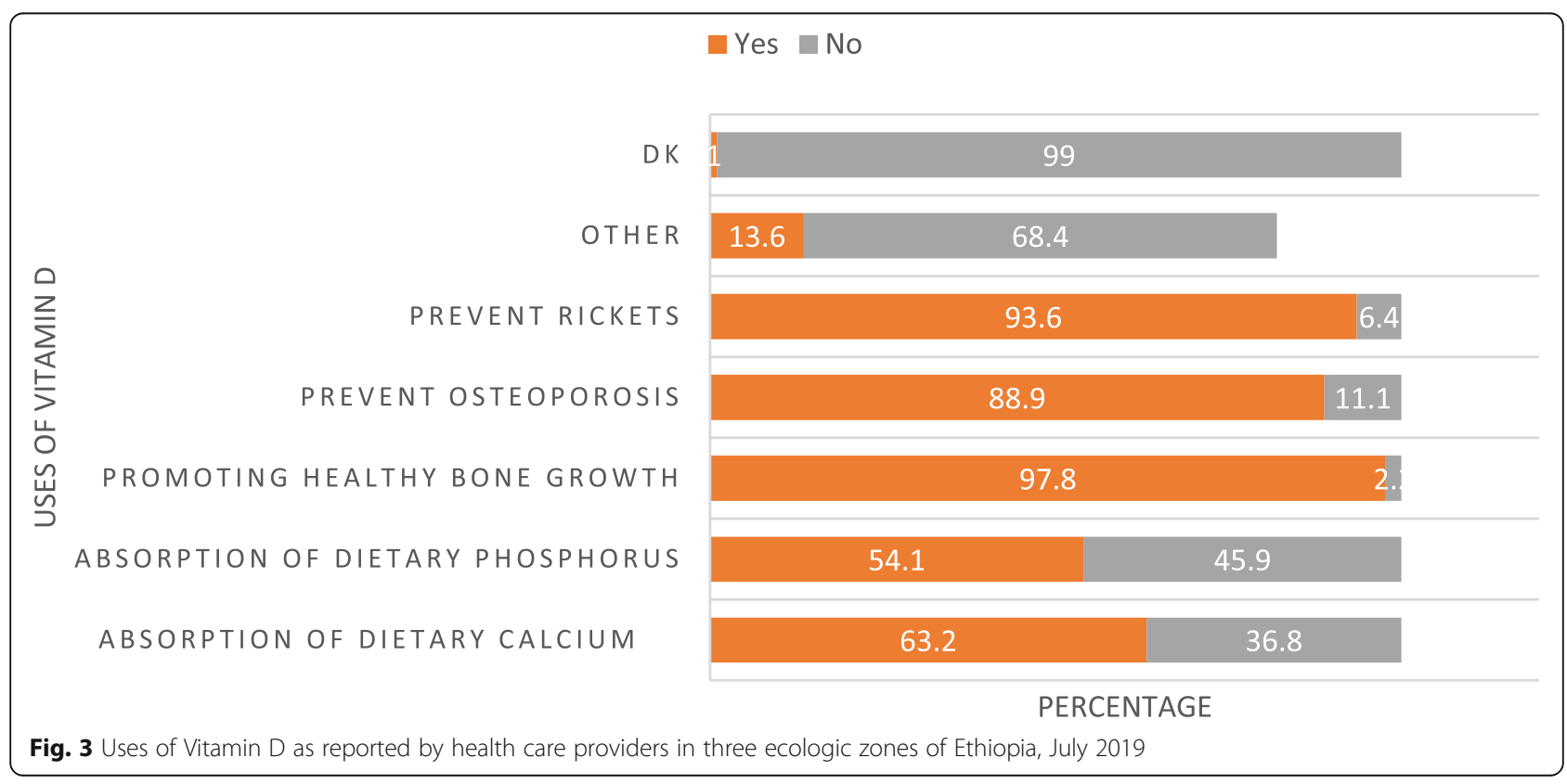




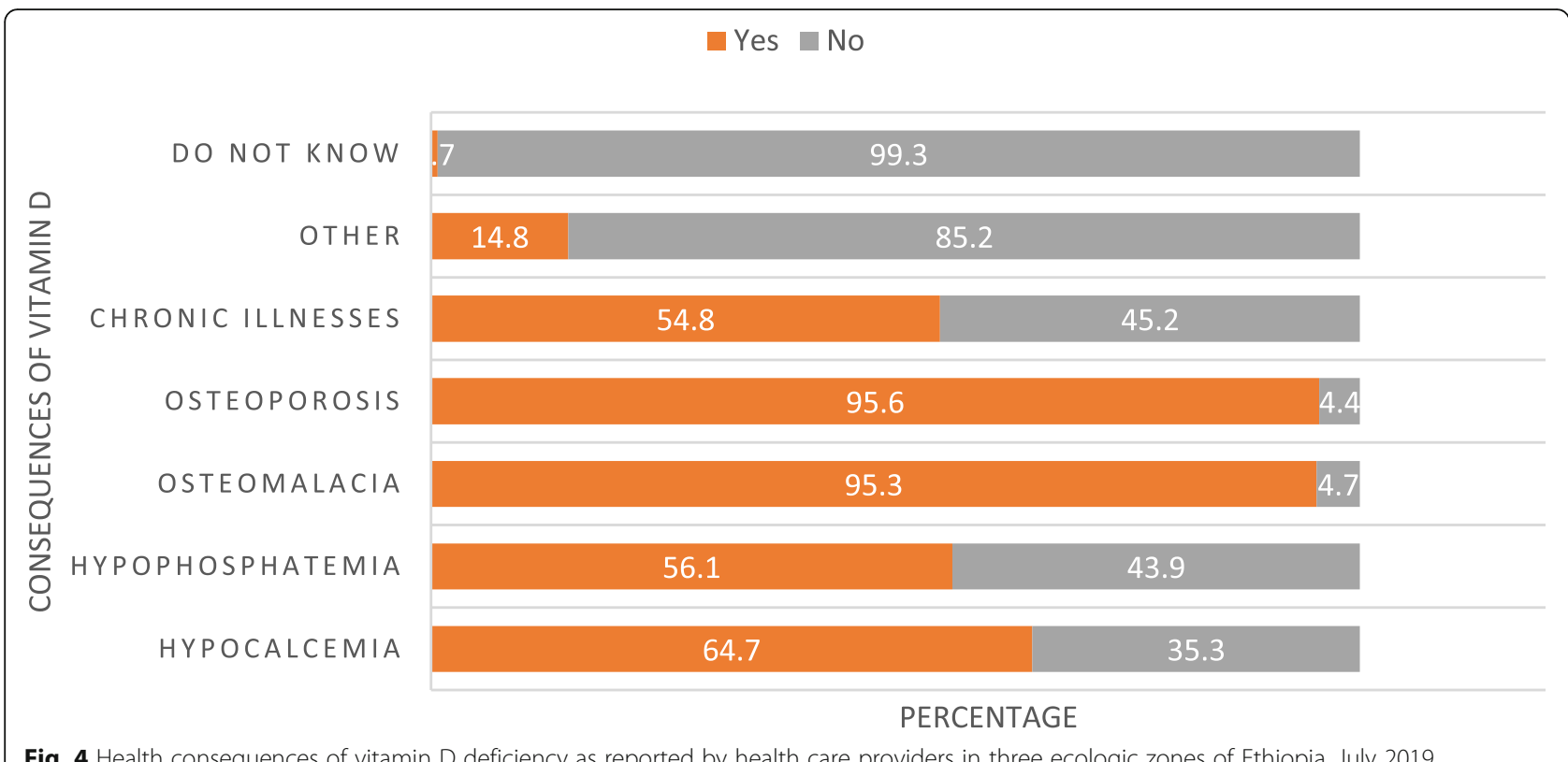

Fig. 4 Health consequences of vitamin D deficiency as reported by health care providers in three ecologic zones of Ethiopia, July 2019

prevention of vitamin D deficiency and treatment of associated diseases. On the other hand, the majority $394(97.3 \%)$ of them reported that there is a need for community sensitization on the deficiency of vitamin D. However, only $13(3.2 \%)$ of them indicated that the ministry of health or regional health bureaus has given adequate attention to the issue under the caption. Though 289(70.6\%) of respondents believed that vitamin D deficiency needs an easy and less costly intervention only a few $7(1.7 \%)$ of them believed that health care providers are adequately trained on measurement of vitamin $\mathrm{D}$ level, diagnosis of its deficiency, and management and treatment of its ill-health consequences. The overall positive attitude score in this study was estimated to be 216 (63.5\%).

\section{Practice of health care providers on adult vitamin D deficiency}

Only 46(11.4\%) of health care workers reported that they have diagnosed adult patients for vitamin $\mathrm{D}$ deficiency in their professional career, of those $26(56.5 \%)$ of them diagnosed 1-3 patients of any age on an average

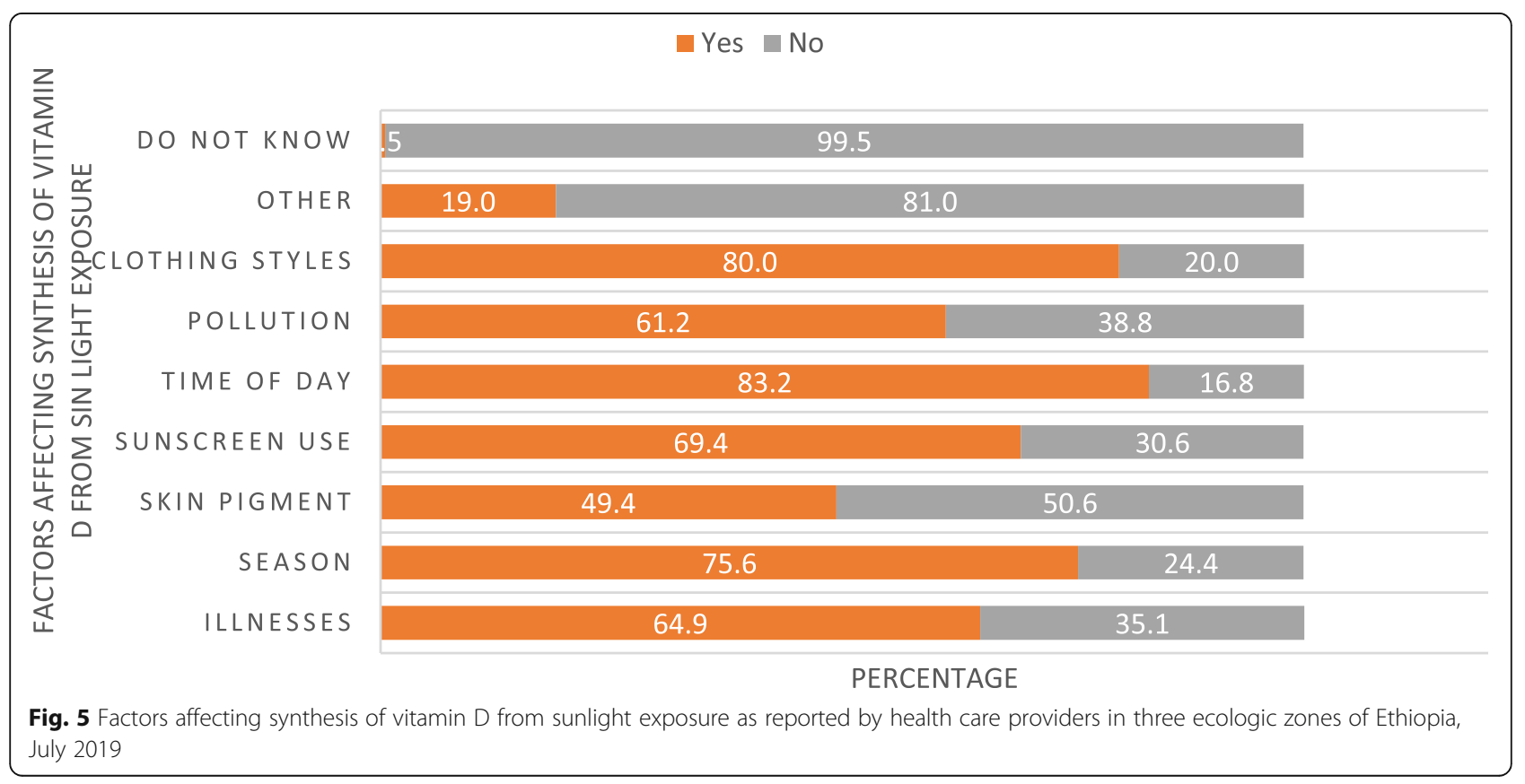




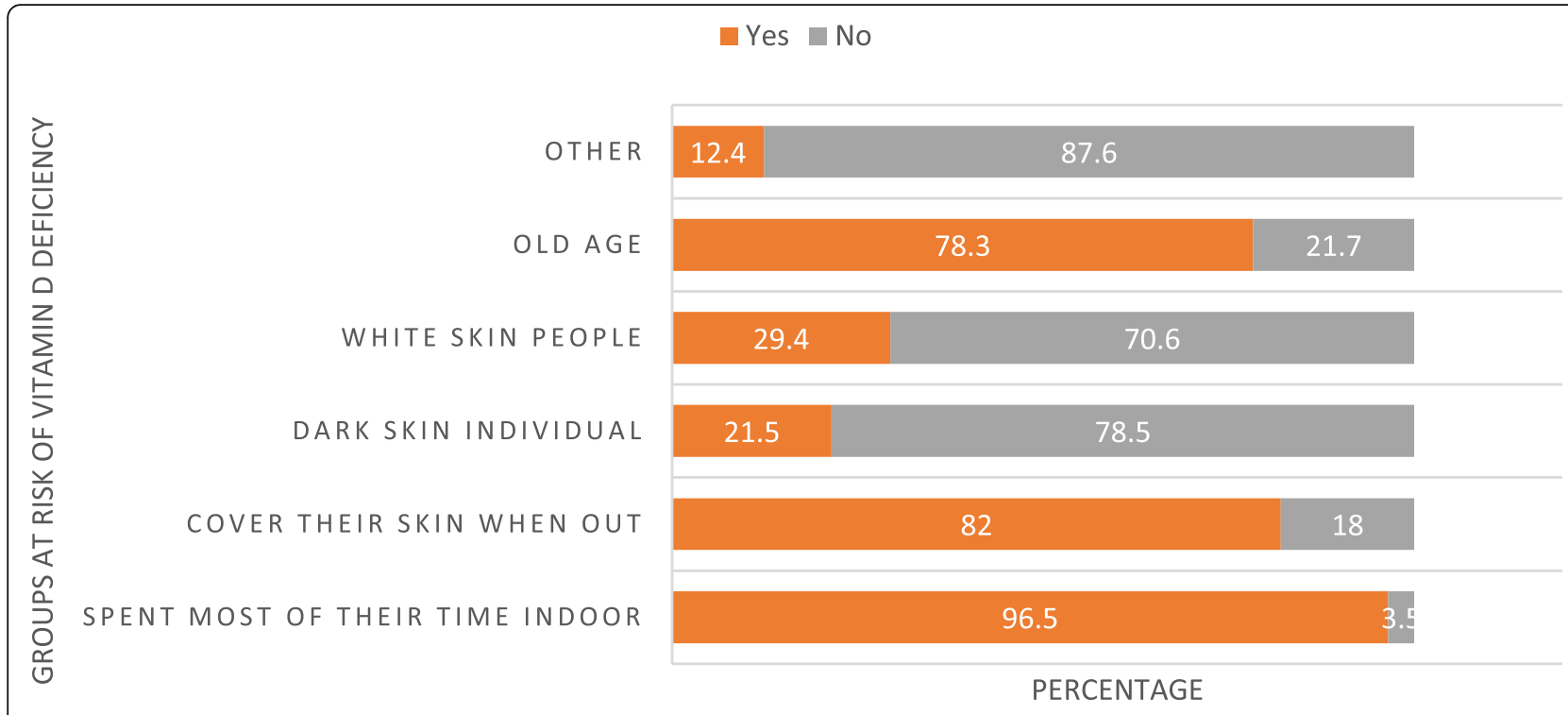

Fig. 6 Population groups at more risk of vitamin D deficiency as reported by health care providers in three ecologic zones of Ethiopia, July 2019

Table 3 Attitude of health care providers towards adult vitamin D level measurement, diagnosis of deficiency and its management and treatment in three ecologic zones of Ethiopia, July 2019

\begin{tabular}{|c|c|c|c|}
\hline \multirow[t]{2}{*}{ Vitamin D Deficiency is a public health problem: } & Yes & 174 & 43.0 \\
\hline & No & 231 & 57.0 \\
\hline \multirow[t]{2}{*}{ There should be universal screening for vitamin D deficiency: } & Yes & 183 & 45.2 \\
\hline & No & 222 & 54.8 \\
\hline \multirow[t]{3}{*}{ There is an adequate laboratory investigation to diagnose Vit $\mathrm{D}$ def: } & Yes & 16 & 4.0 \\
\hline & No & 342 & 8.4 \\
\hline & DK & 47 & 11.6 \\
\hline \multirow[t]{3}{*}{ There is an adequate Vitamin D supplementation in Ethiopia? } & Yes & 45 & 11.1 \\
\hline & No & 303 & 74.8 \\
\hline & DK & 57 & 14.1 \\
\hline \multirow[t]{2}{*}{ Healthcare practitioners adequately aware of prevention and Rx: } & Yes & 66 & 16.3 \\
\hline & No & 339 & 83.7 \\
\hline \multirow[t]{2}{*}{ There is a need for community sensitization on deficiency of vitamin D: } & Yes & 394 & 97.3 \\
\hline & No & 11 & 2.7 \\
\hline \multirow[t]{3}{*}{$\mathrm{MOH} / \mathrm{RHB}$ gave adequate attention to Vitamin D deficiency: } & Yes & 13 & 3.2 \\
\hline & No & 371 & 91.6 \\
\hline & DK & 21 & 5.2 \\
\hline \multirow[t]{2}{*}{ Vitamin D deficiency needs an easy and less costly intervention: } & Yes & 289 & 70.6 \\
\hline & No & 119 & 29.4 \\
\hline \multirow[t]{3}{*}{ Health care providers are adequately trained on vitamin D: } & Yes & 7 & 1.7 \\
\hline & No & 385 & 95.1 \\
\hline & DK & 13 & 3.2 \\
\hline \multirow[t]{2}{*}{ Attitude Score: } & Poor & 150 & 36.5 \\
\hline & Good & 261 & 63.5 \\
\hline
\end{tabular}


working month (see Table 4). When asked on mechanisms of diagnosis $41(89.1 \%)$, did it by making clinical examination, 26(56.5\%) measured serum vitamin D and $21(45.7 \%)$ used a combination of them. Moreover, $26(56.5 \%)$ revealed that they measured a concentration of $25 \mathrm{OH}$ to assess vitamin D status.

Besides, only 50(12.4\%) of study HCWs prescribed vitamin D supplementation for adults recently. Vitamin D supplementation for pregnant women was prescribed by only $3(0.3 \%)$ of the health care workers. Also, $13(3.2 \%)$ of health care workers used guidelines to recommend vitamin D supplementation. This study also revealed that $77(19.0 \%)$ of health care workers have given calcium supplement for adults to prevent the ill consequences of vitamin D deficiency in their fullservice years. In addition to this, 64(15.8\%) of health care providers usually counseled their adult patients about the importance of vitamin D deficiency. Meanwhile, $89(22.0 \%)$ of health care workers have advised adult patients about the source of vitamin D and 53(13.1\%) of them asked their patients about the adequacy of sunlight exposure for vitamin D. Moreover, 86(21.2\%) of health

Table 4 Practice of health care providers on adult vitamin D level measurement, diagnosis of deficiency and its management and treatment in three ecologic zones of Ethiopia, July 2019

\begin{tabular}{|c|c|c|c|}
\hline Variables & & Freq & Per \\
\hline \multirow[t]{2}{*}{ Have you ever diagnosed adult patients for vitamin D deficiency? } & Yes & 46 & 11.4 \\
\hline & No & 359 & 88.6 \\
\hline \multirow[t]{2}{*}{ How many patients of any age do you diagnose in an average month? } & $1-3$ & 26 & 56.5 \\
\hline & 4 plus & 20 & 43.5 \\
\hline \multirow[t]{2}{*}{ Clinically: } & Yes & 41 & 89.1 \\
\hline & & 5 & 10.9 \\
\hline \multirow[t]{2}{*}{ Measuring serum Vitamin D: } & Yes & 26 & 56.5 \\
\hline & & 20 & 43.5 \\
\hline \multirow[t]{2}{*}{ Both: } & Yes & 21 & 45.7 \\
\hline & & 25 & 54.4 \\
\hline \multirow[t]{2}{*}{ Did you measure concentration of $25 \mathrm{OH}$ vitamin $\mathrm{D}$ to assess vitamin D status: } & Yes & 26 & 56.5 \\
\hline & No & 20 & 43.5 \\
\hline \multirow[t]{2}{*}{ Did you prescribe a vitamin D supplement for adults recently? } & Yes & 50 & 12.4 \\
\hline & No & 355 & 87.6 \\
\hline \multirow[t]{2}{*}{ Do you prescribe vitamin D supplements for pregnant women recently? } & Yes & 3 & 0.7 \\
\hline & No & 402 & 99.3 \\
\hline \multirow[t]{2}{*}{ Is there any guideline to recommend for vitamin D supplementation? } & Yes & 13 & 3.2 \\
\hline & No & 392 & 96.8 \\
\hline \multirow[t]{2}{*}{ Have you ever given calcium supplement for adults to prevent the ill consequences? } & Yes & 77 & 19.0 \\
\hline & No & 328 & 81.0 \\
\hline \multirow[t]{2}{*}{ Do you usually counsel your adult patients about the importance of Vit D? } & Yes & 64 & 15.8 \\
\hline & No & 341 & 84.2 \\
\hline \multirow[t]{2}{*}{ Do you advise adult patients about the source of vitamin D? } & Yes & 89 & 22.0 \\
\hline & No & 316 & 78.0 \\
\hline \multirow[t]{2}{*}{ Do you ask your adult patients about adequate sunlight exposure? } & Yes & 53 & 13.1 \\
\hline & No & 352 & 86.9 \\
\hline \multirow[t]{2}{*}{ Do you counsel your adult patients on the need for sunlight exposure for Vit D? } & Yes & 86 & 21.2 \\
\hline & No & 319 & 78.8 \\
\hline \multirow[t]{2}{*}{ Do you ever attend any on the job training/workshop on Vit D deficiency? } & Yes & 26 & 6.4 \\
\hline & No & 379 & 93.6 \\
\hline \multirow[t]{2}{*}{ Practice Score: } & No & 216 & 52.6 \\
\hline & Yes & 195 & 47.4 \\
\hline
\end{tabular}


care workers counseled their adult patients on the need for sunlight exposure to get vitamin D. However, only $26(6.4 \%)$ of health care providers received an on-job training or workshop on diagnosis of deficiency and treatment of vitamin D.

Factors associated with the practice in measuring vitamin D status, diagnosis of deficiency, and management and treatment of its ill health consequences:

The practice in measuring vitamin D status, diagnosis of deficiency, and management and treatment of ill-health conditions is significantly different among providers deployed in the three ecologies, which is higher among health workers working in Addis Ababa followed by those working in the rural highland district (Table 5). Male providers had a significantly better practice compared with females and as the age of the provider increases the practice level is improving. Obviously, clinicians have a better practice compared with those assigned in leadership and health promotion positions though the difference is not statistically significant. The practice level was significantly better among physicians and health officers, whose trainings have more emphasis on clinical orientation. Moreover, those workers who worked for several years had a significantly better practice level compared with the junior ones. In addition to this, health workers who have good knowledge and attitude had better practice in measuring vitamin D level, diagnosis of deficiency, and management of ill-health consequences.

Table 6 showed the binary logistic analysis to identify health care workers' characteristics associated with their practice in measuring vitamin $\mathrm{D}$ level, diagnosing deficiency, and management and treatment of ill-health consequences. The odds of vitamin $\mathrm{D}$ service provision practice was $\mathrm{AOR}=6.87: 95 \% \mathrm{CI}(3.57,13.21)$ times statistically significantly higher among health care workers deployed in Addis Ababa and AOR = 2.20: 95\% CI (1.23, 3.92) times statistically significantly higher in the rural highland compared with those health care workers deployed in the rural lowland area. The likelihood of male health care workers' practice in the provision of vitamin $\mathrm{D}$ related service was $\mathrm{AOR}=1.26: 95 \% \mathrm{CI}(0.71,2.22)$ times statistically significantly higher compared with females. However, the difference in the odds of practice in vitamin $\mathrm{D}$ service provision vanished when it is adjusted for other socio-demographic factors.

Besides, the likelihood of clinicians' practice in the provision of vitamin D service was $\mathrm{AOR}=4.26$ : $95 \% \mathrm{CI}$ $(1.48,12.25)$ times statistically significantly higher compared with those working in leadership and health program positions. The difference in the odds of competency in vitamin D service provision among different professional groups vanished when it is controlled
Table 5 The cross-tabulation of different characteristics of health care providers with the practice of them on measuring level, diagnosing deficiency and its management and treatment in three ecologic zones of Ethiopia, July 2019

\begin{tabular}{|c|c|c|c|}
\hline \multirow[t]{2}{*}{ Variables } & \multicolumn{2}{|c|}{ Practice: \#(\%) } & \multirow{2}{*}{$\begin{array}{l}p- \\
\text { value }\end{array}$} \\
\hline & No & Yes & \\
\hline \multicolumn{4}{|l|}{ Study area: } \\
\hline Addis Ababa & $40(28.6)$ & $100(71.4)$ & \multirow[t]{3}{*}{0.000} \\
\hline Highland & $82(60.7)$ & 53(39.3) & \\
\hline Lowland & $94(72.3)$ & $36(27.7)$ & \\
\hline \multicolumn{4}{|l|}{ Sex: } \\
\hline Male & $78(44.1)$ & 99(55.9) & \multirow[t]{2}{*}{0.001} \\
\hline Female & $138(60.5)$ & $90(39.5)$ & \\
\hline \multicolumn{4}{|l|}{ Age group: } \\
\hline Less than 25 & $48(67.6)$ & 23(32.4) & \multirow[t]{4}{*}{0.000} \\
\hline $25-29$ & 112(58.3) & $80(41.7)$ & \\
\hline $30-39$ & 44(39.3) & $68(60.7)$ & \\
\hline 40 and over & 12(33.3) & $24(66.7)$ & \\
\hline \multicolumn{4}{|l|}{ Role: } \\
\hline Clinician & $197(52.5)$ & $178(47.5)$ & \multirow[t]{2}{*}{0.254} \\
\hline Program officer & 19(63.3) & $11(36.7)$ & \\
\hline \multicolumn{4}{|l|}{ Profession: } \\
\hline Physician & $17(20.0)$ & $68(80.0)$ & \multirow[t]{4}{*}{0.000} \\
\hline Nurse & $99(65.1)$ & $34(34.9)$ & \\
\hline Health officer & $38(53.5)$ & $33(46.5)$ & \\
\hline Health Extension Worker & $62(63.9)$ & $35(36.1)$ & \\
\hline \multicolumn{4}{|l|}{ Service year: } \\
\hline Less than 5 years & 104(55.9) & $82(44.1)$ & \multirow[t]{4}{*}{0.063} \\
\hline $5-9$ years & $70(52.2)$ & $64(47.8)$ & \\
\hline 10-14 years & $31(55.4)$ & 25(44.6) & \\
\hline 15 plus years & 11(31.4) & 24(68.6) & \\
\hline \multicolumn{4}{|l|}{ Knowledge } \\
\hline Poor & $125(64.1)$ & $70(35.9)$ & \multirow[t]{2}{*}{0.000} \\
\hline Good & $91(43.3)$ & $119(56.7)$ & \\
\hline \multicolumn{4}{|l|}{ Attitude: } \\
\hline Poor & $93(62.0)$ & $57(38.0)$ & \multirow[t]{2}{*}{0.004} \\
\hline Good & $123(47.1)$ & 138(52.9) & \\
\hline
\end{tabular}

for other socio-demographic factors. The same is true for the service year of health care workers.

On the other hand, the adjusted odds of practice in vitamin $\mathrm{D}$ service provision was $\mathrm{AOR}=1.96$ : $95 \% \mathrm{CI}$ $(1.19,3.23)$ times statistically significantly higher among those health care workers who have a good knowledge on vitamin D related service compared with those with poor knowledge. Besides, the likelihood of better practice in vitamin $\mathrm{D}$ service provision was $\mathrm{AOR}=2.30$ : $95 \%$ 
Table 6 The binary logistic regression of different characteristics of health care providers with the practice of them on measuring level, diagnosing deficiency and its management and treatment in three ecologic zones of Ethiopia, July 2019

\begin{tabular}{|c|c|c|c|c|}
\hline Variables & Crude OR $(95 \% \mathrm{Cl})$ & $p$-value & Adjusted OR $(95 \% \mathrm{Cl})^{a}$ & $p$-value \\
\hline \multicolumn{5}{|l|}{ Study area: } \\
\hline Addis Ababa & $6.53(3.84,11.10)$ & 0.00 & $6.87(3.57,13.21)$ & 0.00 \\
\hline Highland & $1.69(1.01,2.83)$ & 0.04 & $2.20(1.23,3.92)$ & 0.00 \\
\hline Lowland & 1.00 & & 1.00 & \\
\hline \multicolumn{5}{|l|}{ Sex: } \\
\hline Male & $1.95(1.31,2.90)$ & 0.01 & $1.26(0.71,2.22)$ & 0.43 \\
\hline Female & 1.00 & & 1.00 & \\
\hline \multicolumn{5}{|l|}{ Age group: } \\
\hline $19-25$ & 1.00 & & 1.00 & \\
\hline $25-29$ & $1.49(0.84,2.65)$ & 0.17 & $1.03(0.51,2.08)$ & 0.93 \\
\hline $30-39$ & $3.23(1.73,6.03)$ & 0.00 & $1.98(0.82,4.80)$ & 0.13 \\
\hline 40 and over & $4.17(1.78,9.79)$ & 0.00 & $1.23(0.20,7.52)$ & 0.82 \\
\hline \multicolumn{5}{|l|}{ Role: } \\
\hline Clinician & $1.56(0.72,3.37)$ & 0.26 & $4.26(1.48,12.25)$ & 0.00 \\
\hline Programmer & 1.00 & & 1.00 & \\
\hline \multicolumn{5}{|l|}{ Profession: } \\
\hline Physician & $7.09(3.61,13.90)$ & 0.00 & $1.53(0.53,4.45)$ & 0.43 \\
\hline Nurse & $0.95(0.56,1.61)$ & 0.85 & $0.42(0.20,0.91)$ & 0.03 \\
\hline Health officer & $1.54(0.82,2.87)$ & 0.18 & $0.50(0.20,1.25)$ & 0.14 \\
\hline HEW & 1.00 & & 1.00 & \\
\hline \multicolumn{5}{|l|}{ Service year: } \\
\hline$<5$ years & 1.00 & & 1.00 & \\
\hline $5-9$ years & $1.16(0.74,1.81)$ & 0.52 & $1.06(0.59,1.92)$ & 0.85 \\
\hline $10-14$ years & $1.02(0.56,1.87)$ & 0.94 & $0.91(0.39,2.13)$ & 0.83 \\
\hline 15 plus years & $2.77(1.28,5.98)$ & 0.01 & $1.80(0.33,9.72)$ & 0.49 \\
\hline \multicolumn{5}{|l|}{ Knowledge: } \\
\hline Poor & 1.00 & & 1.00 & \\
\hline Good & $2.34(1.57,3.48)$ & 0.00 & $1.96(1.19,3.23)$ & 0.00 \\
\hline \multicolumn{5}{|l|}{ Attitude: } \\
\hline Negative & 1.00 & & 1.00 & \\
\hline Positive & $1.83(1.22,2.76)$ & 0.00 & $2.30(1.40,3.78)$ & 0.00 \\
\hline
\end{tabular}

HEW Health Extension Worker

${ }^{a}$ Adjusted for study area, sex, age group, role, profession, service year, knowledge and attitude

CI (1.40, 3.78) times statistically significantly higher among those health care workers with a positive attitude in vitamin $\mathrm{D}$ service provision compared with those who did have a negative attitude.

\section{Discussions}

The current study revealed that only a little over half of HCWs in Ethiopia have good knowledge in measuring adult vitamin D levels, diagnosis of deficiency, and management of ill-health consequences. About one in four of study participants thought dietary food sources are good enough for vitamin D, only about 3\% knew mid- day as the best time to sun exposure for vitamin $D$ and $51.1 \%$ knew the ideal duration of sun exposure of $30 \mathrm{~min}$ per day. Teenagers, adults and elderlies, as more risky population groups for vitamin D deficiency, were mentioned by $1.5,1.5$ and $6.9 \%$ of HCWs respectively. On the other hand, a little lower than two-third of participants has a positive attitude towards adult vitamin $\mathrm{D}$ service and $43.0 \%$ think adult vitamin D deficiency is a public health problem. Besides, HCWs with overall good practice of adult vitamin D service provision were 47.4, and $11.4 \%$ of them tried diagnosis of its deficiency among adult patients, and $12.4 \%$ prescribed 
supplementation for adults. Moreover, adult vitamin D service good practice was higher among health workers in Addis Ababa and highland areas compared with those working in lowlands. Male HCWs were more likely to have a good practice on adult vitamin D service compared with females. Clinicians were more likely to have a good practice in adult vitamin D service compared with those working in leadership and health program positions. Good practice in adult vitamin D service provision was higher among HCWs who have a good knowledge and positive attitude compared with their counterparts.

The study revealed gaps in the knowledge of HCWs on adult vitamin $\mathrm{D}$ deficiency. This finding is similar to the findings of similar studies done in Australia and New Zealand $[9,10]$ while it is lower than the finding in Saudi Arabia [23]. This finding is really critical in the sense that if HCWs themselves have a knowledge gap then it will be difficult to manage and treat health conditions due to vitamin $\mathrm{D}$ deficiency which will exacerbate ill-health conditions among adults $[8,9,24]$.

Research shows that sunlight is an important and best source of vitamin D because it produces vitamin D in the skin that may last twice as long in the blood compared with ingested vitamin D [25]. According to Vitamin D Council, dark-skinned individuals need hours of sunlight exposure than light-skinned people. Only half time is needed to produce sufficient amount of Vitamin D before burning the skin. At least $25 \%$ of skin surface has to be exposed. UVB can't penetrate glass windows and there is no overdose of Vitamin D from overexposure to sunlight [26]. However, in the current study, only half of the HCWs identified sunlight exposure as the most common source of vitamin D. The rest of them indicated sources other than sunlight. Because UV radiation is the main risk factor for skin cancer, there is a debate on advice against or recommend sun exposure and physicians are usually confused on encouragement or discouragement of sun exposure as a result some physicians do not recommend their patients to sunlight. But generally, there is a growing evidence and knowledge that suggested insufficient exposure to UV radiation is associated with risks to overall health and even shortens life expectancy [27].

The study also indicated population groups with limited exposure to sunlight as being at high risk of vitamin $\mathrm{D}$ deficiency, including individuals who spend most of their time in indoor activity and old age persons. Studies indicated that dark skin color is considered to be a major factor in vitamin D deficiency [28] and vitamin D concentration differ by color with dark skin individuals producing less vitamin $\mathrm{D}$ compared with light skin individuals in the same amount of sunlight exposure [29, 30]. But in the current study dark skin was identified as a risk factor for vitamin $\mathrm{D}$ deficiency by only one- quarter of the respondents which is similar to a study done in Australia [19].

Another most common confusion among participants was the appropriate time of the day for sun exposure. More than half of the respondents reported morning as an appropriate time for sunlight exposure. Only a very minimal portion $(2.7 \%)$ of $\mathrm{HCW}$ s were able to identify mid-day as an appropriate time for sun exposure to get vitamin D. However previous studies in the area ruled out that mid-day between 10:00 am and 3:00 pm is an appropriate time for sunlight exposure [25]. This implied that HCWs in Ethiopia recommended a wrong time for sunlight exposure to get vitamin D from UV.

The study also revealed that a little less than two-third of study participants have a positive attitude towards adult vitamin D service provision in Ethiopia which has a lot of implication for capacity building of HCWs as it may lead to misdiagnosis of deficiency by frontline health workers which leads to complications of health conditions due to shortage of the mineral considered in this study $[8,9]$.

The study also showed a lot of gap in practice of health care workers in the provision of adult vitamin $D$ service. It is found that a very small percent of HEWs have ever diagnosed vitamin $\mathrm{D}$ deficiency throughout their professional careers. A study done in America also showed physicians do not often consider vitamin D deficiency in their adult patient management and it is very common for them to misdiagnose it [31]. The reason for this may be health care professional often think that their patients in Ethiopia might have adequate sunlight exposure as they are living near the equator. But most of the time, especially aged people, become home bounded and do not get adequate sunlight which predispose them for vitamin $\mathrm{D}$ deficiency [32]. This might be a possible reason for Ethiopian health care workers to ignore vitamin D deficiency in their management of chronic diseases for adults. Although there is a controversy on the cutoff point on level of 25-hydroxyvitamin D, to define vitamin D deficiency, the US Endocrine Society defines vitamin D as 25 -hydroxyvitamin D level below $20 \mathrm{ng} / \mathrm{ml}$ $(50 \mathrm{nmol} / \mathrm{L})$ [33]. In line with this, the study done in Ethiopia in 2013 revealed the prevalence of vitamin D deficiency among adult women was $84.2 \%$ [4]. The small percentage of HCWs who were able to diagnose vitamin D deficiency throughout their career life indicated a missed opportunity in the diagnosis of vitamin D deficiency for patients coming to health facilities. This could be attributed to the poor in-service training that hasn't been given much attention for adult vitamin D deficiency in Ethiopia as documented in this study.

This study also showed a small proportion of HCWs ask and counsel their adult patients about sunlight exposure as documented by different studies that also 
showed physician to miss asking this question [18, 19]. This may be due to either lack of knowledge or minimal attention of health care professionals towards vitamin D or in some cases sunlight exposure is believed to be related with skin cancer. Physicians encourage their patients to use sunscreen when they go out and in some cases they counsel to avoid sunlight exposure because of fear of the risk of skin cancer $[18,19]$.

There is also a major difference and confusion on optimal time and duration of sunshine exposure as evidenced in this study. The study conducted in Saudi Arabia also shows that physicians have different opinions, knowledge, and practice on adult vitamin $\mathrm{D}$ [23]. This difference might be attributed to the use of different guidelines and source of information which implies the Ethiopian government to prepare its own national guideline for adult vitamin D deficiency management.

The study showed that health care workers working in Addis Ababa and rural highland areas in Ethiopia have a better practice of adult vitamin $\mathrm{D}$ service compared with those living in rural lowland areas which could be related to the physicians misunderstanding that people living in arid lowland areas have a better access to sunlight exposure though studies in the middle East indicated the opposite [12, 34].

Generally, since this is the first study done in country, it is believed that, it will give a baseline information on knowledge, attitude, and practice of health care workers on adult vitamin D deficiency which will be used as a reference for future studies.

\section{Strengths and limitations of the study}

Its large sample size, inclusion of respondents from different categories of health workers (health extension workers, nurses, health officers, general practitioners, and specialists), its coverage of different ecological zones (rural and urban areas, highland, midland, and lowland areas) and low none-response rate could be considered as strengths of the study.

The main limitation of the study emanates from its study design in which we cannot establish a causal relationship. On the other hand, though studies suggest cutoff point to dichotomize knowledge, attitude, and practice, there is no standard cut-off point to classify as "good" and "bad" Or "negative" and "positive". The other limitation might be attached to the social desirability bias whereby respondents might report what is presumably acceptable by the research team that may influence the magnitude of knowledge, attitude, and practice.

\section{Conclusions}

The study identifies low level of knowledge, attitude, and practice of health care workers on adult vitamin D status measurement, diagnosis of deficiency, and management and treatment of its health consequences. Moreover, the study reveals that health care workers with good knowledge and a positive attitude have a better practice of adult vitamin D service provision. Besides, female health workers, those working in rural lowland areas and HCWs with non-clinical position were associated with the poor practice of adult vitamin D service provision.

We recommend to have rigorous and continuous inservice trainings on adult vitamin D deficiency for health care workers in different levels of health facilities assuming different positions. Also, special attention should be given to female health care workers, health workers assigned in rural areas where accesses to updated information and technologies are limited, health professionals working in health facilities other than hospitals, and low and mid-level health professionals. To reach at a consensus and avoid confusion regarding the definition, investigation of vitamin $\mathrm{D}$ deficiency and its treatment procedure, the ministry of health and partners working on micro-nutrient supplementation should give better attention to design appropriate national guidelines for adult vitamin $\mathrm{D}$ deficiency management.

\section{Abbreviations}

HCWs: Health care workers; OR: Odds ratio; AOR: Adjusted Odds Ratio; UVB: Ultraviolet B; HCPs: Health care providers; ODK: Open data kit; DK: Don't know; Vit D: Vitamin D; MOH: Ministry of Health; VD: Vitamin D

\section{Acknowledgements}

We thank the Addis Ababa University for funding this project. We are also very grateful for all health care workers involved in this data collection. In addition to this, we thank the field workers involved in the data collection.

\section{Authors' contributions}

Each author developed a sub-thematic research area. WM is the lead for the KAP study and drafted the manuscript. YF was the PI of the thematic research. TZ was involved in the conception and design of the whole research. $\mathrm{JH}$ is a clinical nutritionist who critically revised the proposal. YD was involved in the design of the questionnaire, training, and supervision of the data collection. BL and GT are involved in the design and interpretation of findings. All authors have read and approved the manuscript.

\section{Funding}

The study was funded by the thematic research grant provided for academic staffs of Addis Ababa university. The role of the funding body is to cover associated costs required for data collection. Otherwise, the funding body has no role in the design of the study, analysis, and interpretation of data and in writing the manuscript.

\section{Availability of data and materials \\ The datasets used during the current study are available from the corresponding author on reasonable request.}

\section{Ethics approval and consent to participate}

Ethical clearance was obtained from the institutional review board (IRB) of the College of Health Sciences (CHS) in Addis Ababa University and the School of Public Health (SPH) research ethics committee (REC). Both the $\mathrm{SPH} / \mathrm{REC}$ and $\mathrm{CHS} / \mathrm{RB}$ approved verbal consent since the research did not involve invasive procedure that requires written consent according to the National Research Ethics Guideline [35]. Permission was also secured from the Regional Health Bureaus as well as from the respective district administration and Health Offices. Verbal consent was obtained from each respondent after the objective of the study was explained to all of them in their local language and the right to withdraw from the study at any time 
was also communicated. Anonymity and confidentiality of the information was assured and privacy of each respondent was maintained throughout the data collection process. Information sheet and consent form are uploaded into the Open Data Kit data collection template and archived electronically.

\section{Consent for publication}

Not applicable.

\section{Competing interests}

Authors declare that we do not have competing interests.

\section{Author details}

${ }^{1}$ School of Public Health, College of Health Sciences, Addis Ababa University, Addis Ababa, Ethiopia. ${ }^{2}$ School of Medicine, College of Health Sciences, Addis Ababa University, Addis Ababa, Ethiopia. ${ }^{3}$ Sante Medical College, Addis Ababa, Ethiopia.

Received: 24 August 2020 Accepted: 1 December 2020 Published online: 21 December 2020

\section{References}

1. Binkley N NR KD, Kawahara T, Daida Y, Lensmeyer G, Hollis B, Drezner M. Low vitamin D status despite abundant sun exposure. J Clin End Met 2007;92(6):2130-5. https://doi.org/10.1210/jc.2006-2250.

2. Kočovská E1 AG WP, Halling J, Fernell E, Stóra T, Biskupstø R, Gillberg IC, Shea R, Billstedt E, Bourgeron T, Minnis H, Gillberg C. Vitamin d in the general population of young adults with autism in the faroe islands. J Autism Dev Disord 2014;44(12):2996-3005. https://doi.org/10.1007/s10803014-2155-1.

3. Luxwolda MF KR KI, Dijck-Brouwer DA, Muskiet FA. Traditionally living populations in East Africa have a mean serum 25-hydroxyvitamin D concentration of 115 nmol//. BrJ Nutr 2012;108(9):1557-61. https://doi.org/ 10.1017/S0007114511007161

4. Stoecker TGaBJ. Vitamin D insufficiency in a sunshine-sufficient area: Southern Ethiopia. Food and Nutrition Bulletin. 2013;33(1).

5. Nakhaee S, Ali Yaghoubi M, Zarban A, Amirabadizadeh A, Faghihi V, Yoosef Javadmoosavi S, et al. Vitamin D deficiency and its associated risk factors in normal adult population of Birjand. Iran Clin Nutr ESPEN. 2019;32:113-7.

6. Rai CK, Shrestha B, Sapkota J, Das JK. Prevalence of vitamin D deficiency among adult patients in a tertiary care hospital. JNMA J Nepal Med Assoc. 2019;57(218):226-8.

7. Raza A, Syed JG, Muhammad Ali F, Danish Khan M, Ali Khan M, Haleem F, et al. Incidence of vitamin D deficiency in different seasons in the adult Karachi Population presenting in the medical outpatient department with generalized body ache. Cureus. 2019;11(7):e5167.

8. Law AD, Dutta U, Kochhar R, Vaishnavi C, Kumar S, Noor T, et al. Vitamin D deficiency in adult patients with ulcerative colitis: prevalence and relationship with disease severity, extent, and duration. Indian J Gastroenterol. 2019;38(1):6-14.

9. Wiedemann A, Renard E, Molin A, Weryha G, Oussalah A, Gueant JL, et al. Prolonged $25-\mathrm{OH}$ vitamin D deficiency does not impair bone mineral density in adult patients with vitamin D 25-hydroxylase deficiency (CYP2R1). Calcif Tissue Int. 2020;107(2):191-4.

10. Al-Amri F, Gad A, Al-Habib D, Ibrahim. AK. Knowledge, Attitude and Practice Regarding Vitamin D Among Primary Health Care Physicians in Riyadh City, Saudi Arabia, 2015. World J Food Sci Technol. 2017;1(2):47-55.

11. AlBishi LA, Prabahar K, Albalawi YM, Albalawi SA, Abosalem AA, Alqarni WA, et al. Knowledge, attitude and practice of health care practitioners in Saudi Arabia, with regard to prevention of vitamin D deficiency in infancy. Saudi Med J. 2018;39(6):603-8.

12. Babli Al, AlDawood KM, Khamis AH. Knowledge, attitude, and practice of general practitioners in Dammam, Saudi Arabia towards vitamin D supplementation to infants. J Family Community Med. 2015;22(3):135-9.

13. Damtew Z, Moges A, Kaasbøll J. Revisiting the quality of health extension workers' training: case study from Amhara region, Ethiopia. Ethiopian Health Development. 2011;25(3):201-5.

14. George JA, Norris SA, van Deventer HE, Pettifor JM, Crowther NJ. Effect of adiposity, season, diet and calcium or vitamin $D$ supplementation on the vitamin $\mathrm{D}$ status of healthy urban African and Asian-Indian adults. Br J Nutr. 2014;28(112):4
15. Reeder Al, Jopson JA, Gray AR. Vitamin D insufficiency and deficiency: New Zealand general practitioners' perceptions of risk factors and clinical management. N Z. Med J. 2013;126(1376):124.

16. LH, van der Pols JC, Whiteman DC, Kimlin MG, Neale RE. Knowledge and attitudes about Vitamin D and impact on sun protection practices among urban office workers in Brisbane, Australia. Cancer Epidemiol Biomarkers Prev. 2010;19(7):1784-9. https://doi.org/10.1158/1055-9965.EPI-10-0127.

17. Woolley IJ GM HJ, Korman TM. Unrecognised vitamin D deficiency: Iow concentrations in African migrants with HIV in Australia. Sex Health. 2008;5(4).

18. Reeder Al, Jopson Ja, Gray AR. "Prescribing sunshine": a national, crosssectional survey of 1,089 New Zealand general practitioners regarding their sun exposure and vitamin D perceptions, and advice provided to patients. Bmc Family Prsctice. 2012;13.

19. Bonevski B, Girgis A, Magin P, Horton G, Brozek I, Armstrong B. Prescribing sunshine: a cross-sectional survey of 500 Australian general practitioners' practices and attitudes about vitamin D. Int J Cancer. 2012;130(9):2138-45. https://doi.org/10.1002/ijc.26225.

20. Fentaw $Y$, Woldie $H$, Mekonnen S, Tsegaye AT. Change in serum level of vitamin $D$ and associated factors at early phase of bone healing among fractured adult patients at University of Gondar teaching hospital, Northwest Ethiopia: a prospective follow up study. Nutr J. 2017;16(1):54.

21. Skull SA, Ngeow JY, Biggs BA, Street A, Ebeling PR. Vitamin D deficiency is common and unrecognized among recently arrived adult immigrants from the horn of Africa. Intern Med J. 2003;33(1-2):47-51.

22. CSA. Population Projection for Ethiopia: 2007-2037. 2013: Central Statistical Agency; 2013

23. Al-Amri F, Gad A, Al-Habib D, Khair Ibrahim A. Knowledge, Attitude and Practice Regarding Vitamin D Among Primary Health Care Physicians in Riyadh City, Saudi Arabia. 2017;1(2)

24. Kensara OA, Helal OF, El-Kafy EMA, Ghafouri KJ, Ghaith MM, Alsolami FJ, et al. The combined effect of vitamin D deficiency and hyperparathyroidism on postural stability among healthy adult males. Pak J Biol Sci. 2019;22(9):406-11.

25. Haddad JG, Matsuoka LY, Hollis BW, Hu YZ, Wortsman J. Human plasma transport of vitamin D after its endogenous synthesis. J Clin Invest. 1993; 91(6):2552-2555. https://doi.org/10.1172/JCl116492.

26. Patwardhan VG, Mughal ZM, Chiplonkar SA, Webb AR, Kift R, Khadilkar W, et al. Duration of casual sunlight exposure necessary for adequate vitamin D status in Indian men. Indian J Endocrinol Metab. 2018;22(2):249-55.

27. M.T. Monserrat-García AO-P, P. Martín-Carrasco, J. Conejo-Mir-Sánchez. RFinsufficient exposure to sunlight and global mortality: should we advise against or recommend sun exposure? ACTAS Dermo- sifiliograficas. 2016.

28. McGrath JJ, Kimlin MG, Saha S, Eyles DW, Parisi AV. Vitamin D insufficiency in south-east Queensland. Medical Journal of Australia 2001;174(3):150-151.

29. Akeson P.K. LT, Hernell O., Silfverdal S.A., Ohlund I. Serum vitamin d depends less on latitude than on skin color and dietary intake during early winter in northern europe. J Pediatr Gastroenterol Nutr. 2016;62.

30. Clemens T.L. AJS, Henderson S.L., Holick M.F. Increased skin pigment reduces the capacity of skin to synthesise vitamin d3. Lancet 1.982(1).

31. Lyman D. Undiagnosed Vitamin D Deficiency in the Hospitalized Patient. Am Family Physician 2005 71:2.

32. Richardson J. Vitamin D Deficiency-The Once and Present Epidemic. Am Family Physician 2005 71:2.

33. Holick MF BN, Bischoff-Ferrari HA, Gordon CM, Hanley DA, Heaney RP, et al. Evaluation, treatment, and prevention of vitamin D deficiency : an Endocrine Society clinical practice guideline. J Clin Endocrinol Metabolism. 2011;96(7):1911-30. https://doi.org/10.1210/jc.2011-0385.

34. Haq F, Khan R, Mustehsan Z. Assessment of knowledge, attitude and practices regarding vitamin D among students of Saidu medical college, Swat. Pakistan J Public Health. 2017:7(1):1-4.

35. MOST. The National Research Ethics Guideline. Addis Ababa, Ethiopia: Federal Democratic Republic of Ethiopia, Ministry of Science and Technology; 2014

\section{Publisher's Note}

Springer Nature remains neutral with regard to jurisdictional claims in published maps and institutional affiliations. 